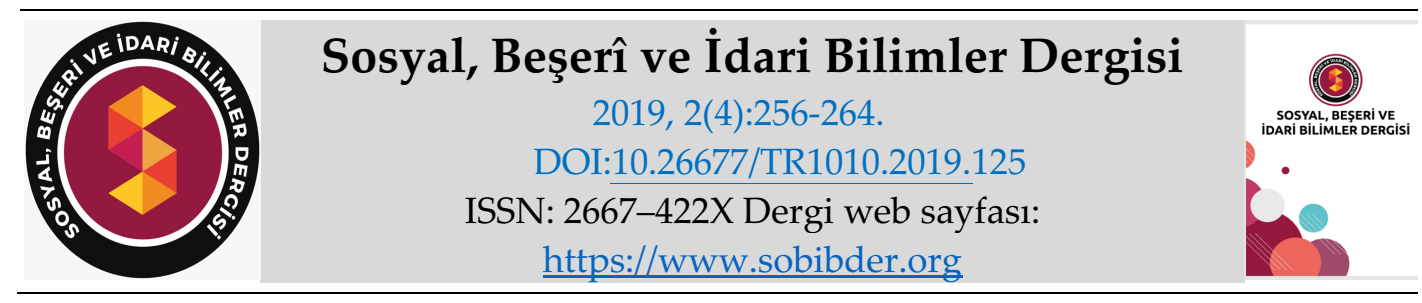

ARAŞTIRMA MAKALESI

\title{
Malatya Sancağı İzolu Nahiyesi Kadığlu ve Pınarlı Karyelerinin Sosyo-Ekonomik Yapısı $(1842-1843)^{*}$
}

Öğr. Gör. Dr. Kazım KARTAL Mehmet Akif Ersoy Üniversitesi, Ağlasun MYO, Burdur, e-posta: kartalkazim44@gmail.com. ORCID: https://orcid.org/0000-0001-5550-6808

\section{$\ddot{O} z$}

Osmanlı Devleti'nde en küçük yerleşim birimi olan karyelerle ilgili önemli kaynaklardan birisi nüfus defterleridir. Bu defterler, o bölgede yaşayan insanların ekonomik ve sosyal durumlarıyla ilgili bilgiler içermektedir. Nüfusa ait bilgiler, sosyal ve ekonomik yapıyı belirleyen önemli göstergeler arasındadır. Bu nedenle biz bu çalışmamızda BOA bulunan 1258 tarihli Nfs kodu 2640 olan Harput eyaleti, (Malatya) sancağı, Malatya, Cubas nahiyesi, İzoli nahiyesi Nüfus defteri kaynak olarak kullanıp İzolu nahiyesine bağlı olan Kadığlu ve Pınarlı karyelerinin sosyo-ekonomik yapısı üzerine değerlendirme yapacağız. Pınarlı ve Kadığlu karyelerinde yaşayan insanların sosyal ve ekonomik yapısı hakkında bilgi verilecektir. Netice itibariyle nüfus defterlerine bağlı olarak, Osmanlı Devleti'nin küçük yerleşim birimi olan Pınarlı ve Kadığlu karyelerinin 19. yüzyılın ortalarında sosyal ve ekonomik durumu değerlendirilecektir.

*Bu çalışma 3-4 Mayıs 2019 tarihleri arasında İKSAD tarafından düzenlenen 4. Uluslararası Tarih ve Kültür Kongresinde sözlü olarak sunulmuştur.

Anahtar Kelimeler: Kelimeler: Osmanlı Devleti, Pınarlı, Kadığlu, Nüfus Defteri.

Makale Gönderme Tarihi: 05.04.2019

Makale Kabul Tarihi: 15.05.2019

\section{Önerilen Atıf:}

Kartal, K. (2019). Malatya Sancağı İzolu Nahiyesi Kadığlu ve Pınarlı Karyelerinin Sosyo-Ekonomik Yapısı (1842-1843), Sosyal, Beşeri ve İdari Bilimler Dergisi, 2(4): 256-264.

(C) 2019 Sosyal, Beşerî ve İdari Bilimler Dergisi. 


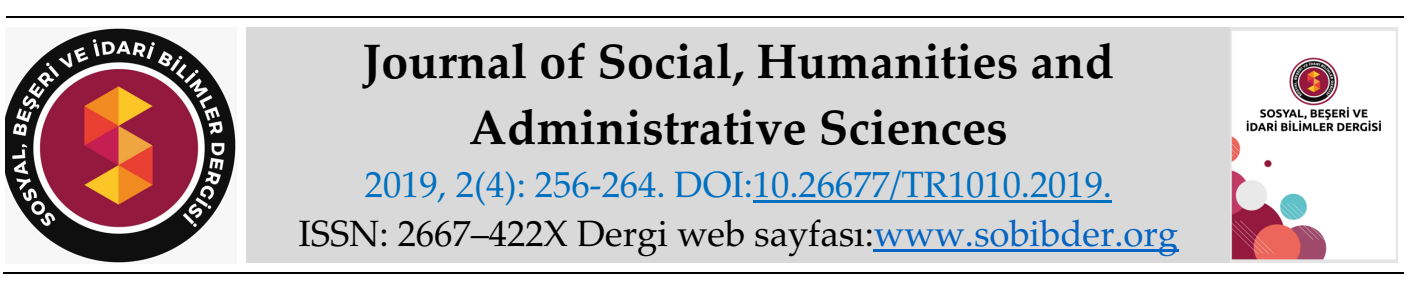

\title{
$\underline{\text { RESEARCH PAPER }}$
}

\section{The Socio-Economic Structure of Malatya Sancagi Izolu Nahiyesi Kadioglu and Pinarli Carians (1842-1843)}

Dr. Kazım KARTAL Mehmet Akif Ersoy University, Ağlasun Vocational High School, Burdur, e-mail: kartalkazim44@gmail.com.

ORCID: https://orcid.org/0000-0001-5550-6808

\begin{abstract}
One of the most important sources in the Ottoman Empire about the carians are the population records. These records contain information about the economic and social situation of people living in that area. Information about the population is one of the most important indicators determining the social and economic structure. In this study, we will use the population registers of Harput state, Malatya, Malatya, Cubas subdistrict, Izoli subdistrict which were found in BOA 1258 with Nfs code 2640 as a source, we will evaluate the socio-economic structure of Kadioglu and Pinarli carians, which are connected to the Izolu district and information about the social and economic structures of the people living in Pinarli and Kadioglu will be given. As a result, depending on the population registers, the social and economic situation of Pinarli and Kadioglu, the carians of the Ottoman Empire mid-19th century, will be evaluated.
\end{abstract}

Keywords: Ottoman Empire, Pinarli, Kadioglu, Population Registers

Received: 05.04.2019

Accepted: 15.05.2019

\section{Suggested Citation:}

Kartal, K. (2019). The Socio-Economic Structure of Malatya Sancagi Izolu Nahiyesi Kadioglu and Pinarli Carians (1842-1843), Journal of Social, Humanities and Administrative Sciences, 2(4): 256-264.

(C) 2019 Sosyal, Beşerî ve İdari Bilimler Dergisi. 


\section{GíRiș}

Osmanlı şehir tarihi araştırılırken başvurulan önemli kaynaklar arasında arşiv belgeleri yer almaktadır. Bu arşiv belgelerinde zaman mekân ve insan unsurunu bir arada barındıran arşiv kaynakları arasında önemli olan kayitlardan biride nüfus defterleridir. Kent nüfusu ve kentin sosyo-ekonomik yapısı bakımından nüfus defterlerinin kent tarihine katkıları oldukça önemlidir. Osmanlı Devleti kuruluşundan itibaren halkın ekonomik yapısını görmek, devletin mali ve askeri ihtiyaçlarını karşılamak için sayımlar yapmış ve bu yaptıkları sayımları ise düzenli olarak kaydetmiştir (Kural, 2018:16). Yapılan sayımlar sonucunda halkın ekonomik durumu ve askerliğe elverişli kişi sayısı tespit edilmiştir (Kartal, 2019:191-225). Yeni fetihler olduğunda ve padişah değişikliklerinden sonra genelde 30 yılda bir sayım ve tespitler merkezi hükümet tarafından yapılmıştır (Barkan, 1940:20-38). Fethedilen bölgenin toprak ve insan profilini ortaya çıarmak için sayımların yapıldığı görülmektedir. Yapılan sayımlarda bekâr erkek çocukları ve her hanenin reisi defterlere kaydedilmiştir. Osmanlı İmparatorluğu XV. ve XVI. yüzyıllarda tımar sistemini uyguladığı bölgelerde vergi mükelleflerin ödeyeceği vergi miktarını, bu vergilerin kimlerin tasarrufunda olduğunu tespit etmek amacıyla tahrir defterleri tutar ve bu konudaki tüm bilgileri sistematik bir şekilde kayıt altına almıştır. Bu defterlere ise mufassal ve icmal defterleri adı verilmekteydi (Kural, 2018:16). Mufassal defterler daha ayrıntılı bilgiler içerirken, icmal defterler ise mufassal defterlerde bulunmayan daha özet bilgilerin mevcut olduğu, dirlik sahiplerinin isimlerini ve gelir toplamlarını veren defter türleridir (Öz, 2010:425-429). Osmanlı İmparatorluğu bu sayımlara önem verdiğini Kemankeş Kara Mustafa Paşanın Sultan İbrahim'e sunduğu lahiyadan sayım hakkında şu sözden de açıkça anlaşılmaktadır: "Tahrir: memleket yazımı demektir. Gayet lâzımdır. Otuz yılda bir kerre tahriri memleket kanundur. Amma gayet Müslüman ve dindar adamlar tayin olunup cümle mahrusa bir uğruna tahrir lazımdır." Defterdarlık yapan Sarı Mehmet Paşa' da bu konuya değinerek, "Reayanın defteri dahi Divani-ali defterhanesinde mazbut olup otuz senede bir tahrir olunup mürde ve marizleri ifraz ve hariç ezdefter olanları müceddeten deftere kaydettirmek lazımdır" diyerek 30 yılda bir sayımın kanun olduğunu ve yapılan tahrirlerin devlet nezdinde önemine değinmiştir (Karal 1997: 6). Osmanlı devleti XIX. yüzyıla kadar nüfus sayımları vergi ve toprak tespiti için yapılıyordu. İmparatorlukta yapılan en erken tahrir sayımı Ömer Lütfü Barkan' a göre I. Murat dönemine aittir. Daha sonraki yüzyıllarda Sultan II. Selim, III. Murat döneminde tahrirler yapılmıştır (Öz, 2010:425-429). Zamanla tımar sistemi önemini yitirmiş ve tahrir faaliyetleri terkedilmiştir. XVI. yüzyılın sonuna kadar olağanüstü hallerde alınan ve gayri mükerrer bir vergi türü olarak ortaya çıan kelime anlamı itibariyle "sonradan meydana gelen, aslî ve sabit olanın zıddı" gibi anlamları bulunan avarız vergisi (Sahillioğlu, 1991: 108-109), uzun süren savaşlar sonucunda devlete maddi açıdan büyük yüklerin binmesi ve devletin nakit ihtiyacını karşılayamaması sonucu, avarız vergisi XVII. yüzyıldan itibaren düzenli toplanan vergi olmuştur (Özel, 2000: 35-50).

Avarız vergisinin düzenli alınması ile birlikte Osmanlı toprak sistemi ve toprağa bağlı olan gelirlerde değişimler olmuştur. Klasik tahrirlerde yer alan ekilebilir toprak büyüklüğü ve ürün miktarı, avarız defterlerinde bulunmazken, hane odaklı veya bireysel olarak yapılan sayımlar bu defterlerde bulunmaktadır (Özel, 2000: 35-50). XVIII. yüzyıl da bu uygulama devam etmiştir (Emecen, 2001:328). Avarız kayıtları bölgesel kayıtlar olması nedeniyle geniş çaplı sayımları barındırmamaktadır. Bu nedenle XVIII. yüzyıl ve öncesinde geniş kapsamlı nüfus sayımlarına rastlanılmamaktadır. XIX. Yüzyıla gelindiğinde ise modern olarak niteleyebileceğimiz nüfus sayımları yapılmıştır.

XIX. yüzyılda Osmanlı Devleti elinde kalan topraklardaki halkın sosyal, iktisadi ve askeri potansiyelini belirleyerek ve otoritesini sağlamlaştırarak nüfusu işlevsel hale getirebilmek için modern anlamda nüfus sayımları yapmıştır. 1826'da Yeniçeri Ocağı kaldırıldıktan sonra 1828-1829'da vergi verebilecek insan sayısını ve orduda istihdam edilecek nüfusu tespit etmek için ilk nüfus sayımları yapılmaya başlanmıştır. Ancak Rusya ile aynı yıl savaşa girilmesi nedeniyle bu sayımlar tamamlanamamış ve savaşın ardından ülke genelinde ilk nüfus sayımları 1830-31 yılları içerisinde yapılmıştı (Carter, 2001:62). 
Biz de bu çalışmamızda BOA bulunan 1258 tarihli Nfs kodu 2640 olan Harput eyaleti, (Malatya) sancağı, Malatya, Cubas nahiyesi, İzoli nahiyesi Nüfus defteri kaynak olarak kullanıp İzolu nahiyesine bağlı olan Kadığlu ve Pınarlı karyelerinin sosyo-ekonomik yapısı üzerine değerlendirme yapılacaktır.

\section{KADIOĞLU KARYESİ SOSYO-EKONOMİK YAPISI}

Sosyo-ekonomik yapıyı ortaya koyan en önemli özellikler lakap ve mesleklerdir. Türk kültüründe lâkap verme geleneği yaygındır. Lâkap: Bir kişiye veya bir aileye kendi isminden ayrı olarak sonradan takılan, o kişinin veya o ailenin bir özelliğinden kaynaklanan ada denir (Seher ve Çalışkan, 2016:104-126). Lâkaplar kişiyi kendi isminden ayrı olarak tanıtan, sonradan konan ve onun belirgin özelliğini gösteren adlardır. Genel ahlâka aykırı olmaması ve ilgili kişinin belli bir çevrede bu lâkapla tanınması kaydıyla ada da dönüşebilmektedir. Türk Ansiklopedisi'nin ilgili maddesinde lâkapların üç olarak gösterilmiştir. Bunlar: "1. Metih yolu, 2. Tarif ve tanıtma, 3. Kötüleme ve hafife alma" şeklinde sayılmaktadır (Coşar, 2003:27-40) İslam Ansiklopedisinin ilgili maddesine baktığımızda ise Lakap; “övgü veya yergi ifade eden isim ve sıfat" anlamındadır. Cahiliye döneminde kişinin, adından başka sonradan toplumun verdiği bir de lakabı olur, onun fizik veya karakter yapısını yansıtan bu lakap bazen takdir, bazen tahkir ifade ederdi (Bozkurt, 2003:65-67). Osmanlı Devletinde de Anadolu'da ailelerin birbirini tanıması için sülale veya soyadı geçen mutlaka bir lakabı vardı. Fakat bu lakap çekirdek aileye değil birbiriyle akrabalık bağı olan bir sülaleye aitti. Bu nedenle Anadolu'nun kasaba ve şehirlerinde insanlar birbirini lakabından tanırdı. Cumhuriyet'in ilk yıllarında ve 1934 yılında Soyadı Kanunu'nun kabulünden sonra uzun süre devam eden bu gelenek son dönemlerde yaşanan yoğun göç olgusu ile giderek etkisini kaybetmiştir. Soyadı Kanunu'nun kabulüyle birlikte uygun olan bazı lakaplar aynen veya bazı değişikliklerle soyadı olarak da alınmıştır (İpşirli, 2003:65-67). Günümüzde kırsal kesimlerde halk arasında da hala lakaplar ile halk birbirini kimliksel olarak tanımaktadır. Çalışmamıza konu olan nüfus defterinde geçen lakaplar aşağıdaki gibidir (BOA, NFSd, no:1258). (Tablo 1)

\section{Tablo 1: Kadığlu Karyesinde Lakaplar}

\begin{tabular}{|l|l|l|l|}
\hline Sira no & Lakaplar & Sira no & Lakaplar \\
\hline 1 & Kadığlu & 15 & Dezooğlu \\
\hline 2 & Hacoğlu & 16 & Paşooğlu \\
\hline 3 & Ziyaloğlu & 17 & Yiğitbaşığlu \\
\hline 4 & Bozooğlu & 18 & Hacı Mustafaoğlu \\
\hline 5 & Herdlioğlu & 19 & Davudoğlu \\
\hline 6 & Ömeroğlu & 20 & Murtazaoğlu \\
\hline 7 & Alioğlu & 21 & Mamooğlu \\
\hline 8 & Osmanoğlu & 22 & Yusufoğlu \\
\hline 9 & İrahimoğlu & 23 & İbrahimoğlu \\
\hline 10 & Gidooğlu & 24 & Sakatoğlu \\
\hline 11 & Tahiroğlu & 25 & Ağcuoğlu \\
\hline 12 & Ahmedoğlu & 26 & Hacooğlu \\
\hline 13 & Battaloğlu & 27 & Osmanoğlu \\
\hline 14 & İsmailoğlu & 28 & Nebioğlu \\
\hline
\end{tabular}

\section{Meslekler}

Meslekler, bir bölgenin iktisadi yapısını ortaya koyması açısından önem arz etmektedir. Kadıŏlu karyesinde bulunan meslekler Çiftçi, Rençber ve Askerlik vazifesini yerine getiren kişilerden oluşmaktadır. Çiftçi ile Rençber ayrı kaydedildiği görülmektedir. Zira Rençber kelimesi köken olarak 
Farsçadır. Istırap, zahmet, eziyet anlamındaki renc kelimesinden gelmiştir. Ancak zaman içerisinde Türkçeleşmiş bir kelimedir ve genel kullanım şekliyle toprak işçiliği ile ilgilidir (Talci, 2002:714-717). Toplum düşüncesi, toprakla uğraşan herkesi Rençber olarak nitelendiriyor olmakla beraber, İktisat literatüründe ise toprakla uğraşan herkes Rençber olarak nitelendirilmemektedir. Çiftçi ile Rençber kavramları, aynı defter içerisinde art arda, farklı kişiler olarak kaydedilmiştir. Anlaşıldığı kadarıyla burada kendisi arazi sahibi olduğu halde toprağı işleyenler Çiftçi, kendi mülkü olmaksızın başkasının arazisinde işçi olarak çalışan kişiler veya arazi ve hayvan kiralamak suretiyle uğraşan kişiler ise Rençber olarak adlandırılmaktadır. Çalışmamıza konu olan nüfus defterinde geçen mesleklere baktığımızda Kadıŏlu karyesinin iktisadi yapısı ve sosyal yapısı üzerine kısa bir değerlendirme yapacak olursak tarım ürünlerine bağlı olup üretici nüfusa sahiptir. Ancak şu da bir gerçektir ki iktisadi açıdan ve sosyal açıdan tarıma bağlı nüfusun olduğu ve sanayi, sağlık ve eğitim açısından geri kalmış olduğunu söylemek mümkündür. Ayrıca Çiftçi sayısının Rençber sayısından fazla olması ise halkın kendi topraklarında çalışmış olduğu ancak Rençber sayısında azımsanmayacak sayıda kişilerin olması ise halkın sosyal ve iktisadi seviyesinin iyi olmadığını bizlere göstermektedir. Kadığlu karyesinde yaşayan 32 kişiden 10 kişi Rençber konumundadır. Bu da yaklaşık olarak \%32 kişiye tekabül etmektedir (BOA, NFSd, no:1258). (Tablo 2).

Tablo 2: Meslekler

\begin{tabular}{|l|l|l|l|}
\hline Sıra no & Meslek adi & Kişi sayısı & Yaş ortalaması \\
\hline 1 & Çiftçi & 19 & 48 \\
\hline 2 & Rençber & 10 & 41 \\
\hline 3 & Piyade-hassa, Asitane & 4 & 20 \\
\hline
\end{tabular}

\section{PINARLI KARYESI SOSYO-EKONOMIK YAPISI}

Pınarlı karyesinde bulunan 33 kişinin lakapları şu şekildedir: Teloğlu(4), Darıca Mehmedoğlu (9), Ömeroğlu (8), Hüseyinoğlu (1), Osmanoğlu (2), Çukadaroğlu (2), Mustafaoğlu (5), Güloğlu(2) lakapları bulunmaktadır ( BOA, NFSd, no:1258 ). (Tablo 3)

Tablo 3: Pınarlı karyesinde bulunan kişilerin lakapları

\begin{tabular}{|l|l|}
\hline Sira no & Lakaplar \\
\hline 1 & Telooğlu \\
\hline 2 & Darıca Mehmedoğlu \\
\hline 3 & Ömeroğlu \\
\hline 4 & Hüseyinoğlu \\
\hline 5 & Osmanoğlu \\
\hline 6 & Çukadaroğlu \\
\hline 7 & Mustafaoğlu \\
\hline 8 & Güloğlu \\
\hline
\end{tabular}




\section{Meslekler}

Mesleklere baktığımızda 33 kişi içerisinde bir kişinin askerde bulunduğu diğer kişilerin ise Çiftçi ve Rençber olduğu görülmektedir. Toplamda 9 kişi meslek olarak kaydedilmiştir. Bu durum aslında burada yaşayan kişilerin büyük çoğunluğunun işsiz olduğunu bizlere göstermektedir. (Tablo 4)

Tablo 4: Pinarlı Karyesinde bulunan meslekler

\begin{tabular}{|l|l|l|l|}
\hline Sıra no & Meslek adi & Kişi sayısı & Yaş ortalaması \\
\hline 1 & Çiftçi & 6 & 39 \\
\hline 2 & Rençber & 2 & 38 \\
\hline 3 & Piyade-hassa, Asitane & 1 & 20 \\
\hline
\end{tabular}

\section{SONUÇ}

Bu çalışmamıza konu olan defter, Başbakanlık Osmanlı Arşivi'nde, bulunan 1258 tarihli NFS kodu 2640 olan Harput eyaleti, (Malatya) sancağı, Malatya, Cubas nahiyesi, İzoli nahiyesi nüfus defteridir. Araştırmada, Osmanlı Devleti'nin, 1842 yılında Malatya sancağında yapılan ilk nüfus sayım kayıtlarını içermektedir. 1842 yılındaki arşiv kayıtları üzerinden XIX. yüzyıl ortalarında Kadıŏ̆lu ve Pınarlı karyelerinin sosyal ve iktisadi yapısı ortaya konulmuştur. Ayrıca defter oldukça düzenli tutulmuş ve nüfus kaydı ile ilgili ayrıntılı ilk elden bilgiler sunmaktadır.

2640 numaralı nüfus defterine göre Kadığlu ve Pınarlı karyelerinin kayıtları meslek grupları ve lakaplar tespit edilip tablolar halinde düzenlenmiştir. İktisadi açıdan değerlendirildiğinde her iki karyede de tarıma yönelik bir iş̧̧i grubunun olduğunu söylemek mümkündür. Ayrıca Pınarlı karyesinde yaşayan kişilerin Kadığlu karyesine oranla daha az gelire sahip olup ve işsizlik oranı daha fazladır. Bu durum bize Kadıŏ̆lu karyesinin Pınarlı karyesine oranla yaşam standartlarının daha iyi olduğunu göstermektedir. Sonuç olarak her iki karyede işgücü tarım ürünlerine yönelik olup, her iki karyede işsizlik oranları fazladır.

\section{Arşiv Kaynakları}

BOA, NFSd, no:1258.

\section{KAYNAKÇA}

Altı, Aziz. (2018). Makedonya'da Bir Bektaşi Köyü: Kanatlar, Ankara Hacı Bayram Veli Üniversitesi IV. Uluslararası Alevilik ve Bektaşilik Sempozyumu, C. 1 içinde (ss.67-90), Ankara.

Barkan, Ö. L. (1940). Türkiye'de İmparatorluk Devirlerinin Nüfus ve Arazi Tahrirleri ve Hakana Mahsus İstatistik Defterleri-I, İktisat Fakültesi Mecmuası, 2(1):20-38.

Bingül, Ş. (2016). (H.1252/M.1836) Yılı Nüfus Sayımına Göre Van Kazasına Bağlı Gayrimüslim Köylerin Demografik Yapisi, Journal of History and Future, 3, 101-116.

Bingül, Ş. (2016). H.1252/M.1836) Yılı Nüfus Sayımına Göre Van Kazasına Bağlı Müslim Köylerin Demografik Yapısı, Tarih Okulu Dergisi, XXVI (ss. 87-115).

Bozkurt, N. (2003). "Lakap", Türkiye Diyanet Vakfı İslam Ansiklopedisi, C.27 içinde (ss.65-67). Ankara: Türkiye Diyanet Vakfı Yayınları.

Carter, F. V. (2011). Modern Türkiye Tarihi (1789-2007), İstanbul: Timaş Yay. 
Coşar, A. M. (2003). Trabzon'da Kullanılan Lâkaplar Üzerine Bir Derleme/Değerlendirme, Türk Dili Araştırmaları Yıllı̆̆ı Belleten, 12(42): 27-40.

Emecen, F. M. (2011). Osmanlı Klasik Çağında Hanedan Devlet ve Toplum. İstanbul: Timaş Yayınları.

İpşirli, M. (2003). “Lakap”, Türkiye Diyanet Vakfı İslam Ansiklopedisi, C.27 içinde (ss.65-67). Ankara: Türkiye Diyanet Vakfı Yayınları.

Karpat, K. H. (2010). Osmanlı Nüfusu 1830-1914. (Çev. Bahar Tırnakçı). İstanbul: Timaş Yayınları

Kartal, K. (2019). Tanzimat Süresince Diyarbakır'ın Sosyal ve Ekonomik Yapısı Üzerine Bir Değerlendirme (1847/1848), (Editör) Oktay Bozan ve Hakan Asan vd., Tanzimat'tan Günümüze Diyarbakır C.1 içinde, (ss.191-225) Ankara: Manas Yay.

Karal, E. Z. (1997). Osmanlı İmparatorluğunda İlk Nüfus Sayımı 1831, T.C. Başbakanlık Devlet İstatistik Enstitüsü, Ankara.

Kural, N. (2018). 2794-2795 Numaralı Gevaş-Vastan-Karçıkan-Havasor Nahiyelerinin Müslim-Gayrimüslim Nüfus Defterleri'nin Transkripsiyon Ve Değerlendirilmesi, Yayınlanmamış Yüksek Lisans Tezi, Mardin Artuklu Üniversitesi, Mardin.

Seher, Ş. ve Çalışkan, E. (2016). “Türk Folklorunda Lâkap Verme Geleneği: Bartın Örneği”, Manisa Celal Bayar Üniversitesi Sosyal Bilimler Dergisi, .14, 104-126.

Öz, M. (2010). “Tahrir”, Türkiye Diyanet Vakfi İslam Ansiklopedisi Cilt 39 içinde (ss.425-429) İstanbul: Türkiye Diyanet Vakfı Yayınları.

Özel, O. (2000). Avarı ve Cizye Defterleri, Osmanlı Devleti'nde Bilgi ve İstatistik, (Derleyen) Halil İnalcık, Şevket Pamuk, T.C. Başbakanlık Devlet İstatistik Enstitüsü, (ss. 35-50). Ankara.

Sahillioğlu, H. (1991). "Avarız", Türkiye Diyanet Vakfı İslam Ansiklopedisi Cilt 4 içinde (ss.108-109.) İstanbul: Türkiye Diyanet Vakfı Yayınları.

Telci, Cahit, (2002), Osmanlı İktisat Literatüründe Bulunan ve Günümüzde Hâlâ Yaşayan Bir Kavram: Rençber, Türkler Ansiklopedisi, C.10 içinde (ss.714-717). Ankara. 


\section{Ek 1: Pınarlı Karyesi}

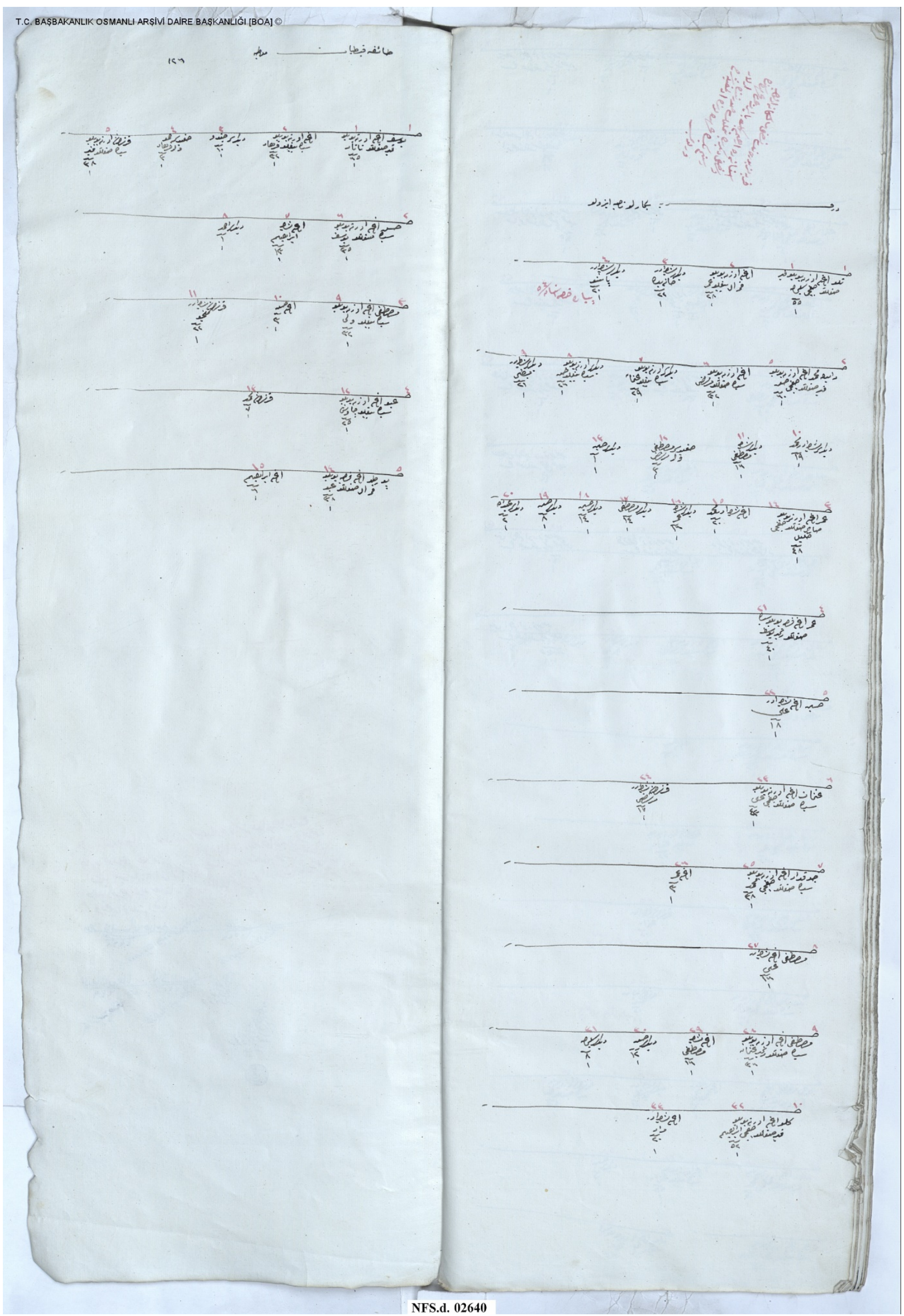




\section{Ek:2: Kadıŏglu Karyesi}

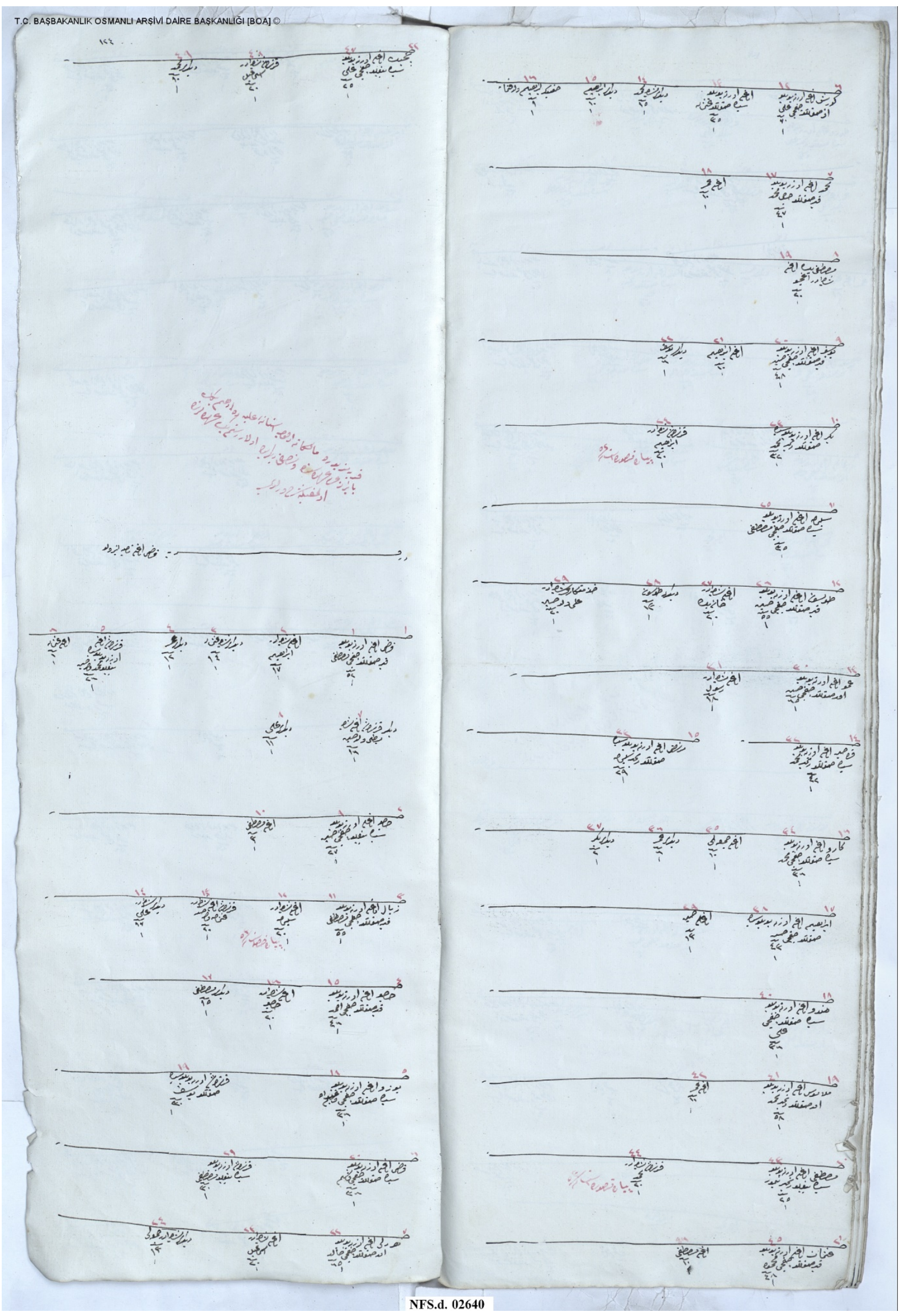

